FETAL AND NEONATAL EDITION

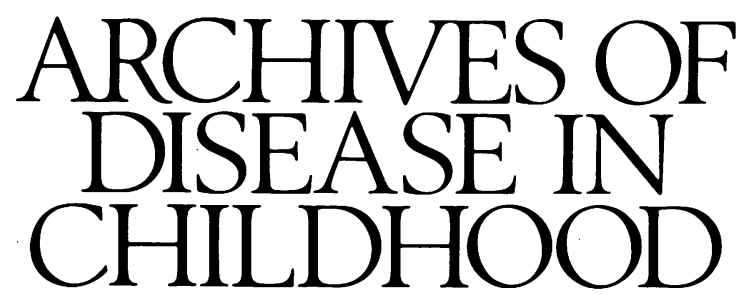

The fournal of the British Paediatric Association

\title{
Alternatives to ECMO
}

Nothing epitomises the technological advances in neonatal medicine more than extracorporeal membrane oxygenation (ECMO) treatment. This technique has dramatically improved the survival of infants with presumed intractable respiratory failure. ${ }^{1}$ Data from the Extracorporeal Life Support Organization Registry as of July 1993 show an overall survival rate of $81 \%$ for 8020 treated newborns. $^{2}$

ECMO has been embraced as a standard treatment in much of the world despite a paucity of controlled clinical trials. Two studies performed in the United States, using an adaptive randomisation design, achieved statistical significance and were terminated without many control patients and left many questions unanswered. ${ }^{34}$ In the ensuing years, use of neonatal ECMO has proliferated in spite of the fact that other respiratory treatment modalities and clinical strategies are now available which are less technical, less expensive, less invasive, and less labour intense. Most of these 'alternative' strategies are routinely available to neonatal intensive care units and have demonstrated the potential to relegate ECMO to its most effective role as a rescue treatment when more conventional therapy fails.

\section{ECMO candidates}

Patients considered for ECMO treatment are generally $\geqslant 2000 \mathrm{~g}$ and 34 weeks' gestation and have intractable - but reversible - respiratory failure within the first 10 days of life..$^{5}$ The causes of respiratory failure are diverse and include meconium aspiration syndrome, respiratory distress syndrome, sepsis/pneumonia, congenital diaphragmatic hernia, and others. Virtually all of these conditions involve secondary persistent pulmonary hypertension of the newborn (PPHN), and although management strategies differ from one condition to the next, alleviation of pulmonary hypertension and establishment of pulmonary blood flow is something they share as a common therapeutic goal.

\section{Basic supportive measure}

No matter what criteria are utilised to constitute indications for ECMO, they all presuppose that the infant has received 'optimal medical management'. This includes the appropriate ventilatory modality and strategy, which is disease specific (see below). Support of systemic blood pressure is of the utmost importance in assuring tissue perfusion and decreasing right-to-left shunting of blood. Initial management consists of cautious expansion of blood volume (colloid, blood, or crystalloid) by up to 20 $\mathrm{ml} / \mathrm{kg}$. Central venous pressure monitoring is a useful adjunct and helps to determine the need for additional volume or inotropic support (dopamine, $2.5-15 \mu \mathrm{g} / \mathrm{kg} / \mathrm{min}$; dobutamine, $5-20 \mu \mathrm{g} / \mathrm{kg} / \mathrm{min}$; or isoprenaline, $0.1-0.4$ $\mu \mathrm{g} / \mathrm{kg} / \mathrm{min}$ ). Oxygen carrying capacity should be maximised by transfusion to maintain a packed cell volume above $0 \cdot 4$. Detection of impaired oxygen delivery, tissue oxygen extraction, or both may be made by monitoring mixed venous blood gases or oximetry. ${ }^{6}$ Surfactant deficiency should be corrected by exogenous surfactant administration. Antimicrobials should be given in cases where infection is presumed or proved. Vasodilator treatment (tolazoline $1-2 \mathrm{mg} / \mathrm{kg} /$ hour) may be beneficial in reducing pulmonary vascular resistance but must be used with great caution because of its non-selective nature and tendency to provoke systemic hypotension. ${ }^{7}$

\section{Alternative modalities}

Infants unresponsive to conventional ventilatory techniques and basic supportive treatment may benefit from alternative treatment modalities. Unfortunately, there have been no controlled clinical trials which compare these modalities to each other or to ECMO. Utilisation has generally occurred as a rescue intervention or on the basis of clinical empiricism. Nevertheless, these treatments do suggest potential benefits and avoidance of ECMO.

\section{Hyperventilation}

Long the standard approach to PPHN in the United States, hyperventilation attempts to achieve significant alkalosis and hypocapnia through both metabolic and respiratory means. Target $\mathrm{pH}$ is usually $7 \cdot 50-7 \cdot 70$ and arterial carbon dioxide tension $\left(\mathrm{PaCO}_{2}\right) 2 \cdot 0-4 \cdot 0 \mathrm{kPa}$ during the acute phase. Sedatives and paralytics are used liberally. 
The physiological basis for this approach is the observation that alkalosis and hypocapnia exert independent effects on reducing pulmonary arterial pressure and improving pulmonary perfusion. ${ }^{89}$ This approach is modified at 72-96 hours when the infant reaches the 'transition stage' and exhibits less vascular responsiveness.

\section{Conservative ventilation}

This technique is almost diametrically opposed to hyperventilation. Developed by Wung et al, this approach is aimed at using the least possible ventilator support to achieve satisfactory gas exchange, thus limiting the adverse effects of barotrauma and hyperinflation. ${ }^{10}$ Target blood gases reflect these goals, where $\mathrm{pH}$ is kept from $7 \cdot 25-7 \cdot 40$, $\mathrm{PaCO}_{2} 5 \cdot 3-8 \cdot 0 \mathrm{kPa}$ and arterial oxygen tension $\left(\mathrm{PaO}_{2}\right)$ from $6 \cdot 7-9 \cdot 3 \mathrm{kPa}$. Paralytics are not used and sedatives are minimised so as not to depress respiratory drive. Wung et al reported $100 \%$ survival of 15 infants treated this way, who had had a predicted mortality of $80 \% .{ }^{10}$ Dworetz et al reported $90 \%$ survival in 10 patients. ${ }^{11}$ Both series were non-randomised and uncontrolled.

\section{High frequency ventilation}

This form of positive pressure ventilation uses extremely small tidal volumes (less than anatomical deadspace) provided at very rapid rates to produce gas exchange at lower mean airway pressure than conventional ventilation. ${ }^{12}$ High frequency jet ventilation (HFJ) uses a jet injector to deliver a high velocity gas flow at rates of $240-660$ breaths $/ \mathrm{min}$. Expiration is passive. High frequency oscillatory ventilation (HFOV) uses either a piston or vibrating diaphragm to deliver tidal volumes at rates of up to $3600 \mathrm{breaths} / \mathrm{min}$. Both inspiration and expiration are active.

HFJV has had some success when applied to ECMO candidates. Baumgart et al reported $100 \%$ survival if applied to infants with an oxygenation index (mean airway pressure $\left(\mathrm{cm} \mathrm{H}_{2} \mathrm{O}\right) \times$ fractional inspired oxygen $/ \mathrm{PaO}_{2}$ $(\mathrm{mm} \mathrm{Hg}))<0.4$, and $84 \%$ survival in 38 patients with respiratory distress syndrome or pneumonia. ${ }^{13}$ Similarly, Hart et al described a $48 \%$ survival rate over a three year period in an ECMO centre. ${ }^{14}$ Using HFOV, Carter et al successfully managed $50 \%$ of near term infants with severe respiratory failure who had met ECMO indications. ${ }^{15}$ Although high frequency ventilation is relatively easy to use, it requires careful analysis of the strategy to be utilised, based on the homogeneity of the lung disease, lung volume, and whether the primary deficiency is ventilation or oxygenation.

\section{Volume cycled ventilation}

Volume cycled ventilation refers to the delivery of a preset tidal volume delivered at whatever pressure is necessary to do so. ${ }^{16}$ Although it was used frequently in the late 1970 s and early 1980 s, design flaws and insufficient monitoring capabilities led to its disappearance from neonatal nurseries. Now, however, microprocessor based technology and state of the art monitoring has enabled the use of volume cycled ventilation in infants as small as $2000 \mathrm{~g}$. Bandy et al reported on a non-randomised, quasiexperimental series of ECMO candidates treated with volume cycled ventilation after time cycled pressure limited ventilation failed. ${ }^{17}$ All six of the infants showed dramatic improvement in oxygenation, at the same mean airway pressure, and all avoided ECMO. Pulmonary mechanics testing revealed much more consistent tidal volume delivery during volume cycled ventilation, perhaps stabilising lung volumes and decreasing ventilationperfusion mismatch.

\section{Liquid ventilation}

This technique, which must still be considered investigational, involves the use of a liquid medium, a perfluorocarbon, to inflate the lungs and serve as a medium for gas exchange. Perfluorocarbons are able to do this because of low surface tension and high oxygen solubility; they are also biologically inert. Human neonatal experience to date has been minimal. Shaffer et al reported the use of liquid ventilation in three dying infants. ${ }^{18}$ Before death improved compliance was demonstrated in all three, and improved oxygenation in two. Although much more study is required, it appears that some patients might derive benefit from the technique.

\section{Nitric oxide}

Nitric oxide has been identified as the long elusive endothelial derived relaxing factor, which binds to haemoglobin and results is relaxation of vascular smooth muscle cells. ${ }^{19}$ Animal experience has demonstrated that inhaled nitric oxide is a potent pulmonary vasodilator with a sustained effect which does not decrease systemic blood flow. Early human neonatal experience in ECMO candidates has been favourable. Roberts et $a l^{20}$ and Kinsella et $a^{21}$ successfully treated a total of 15 patients during short term evaluation. Marked improvement in preductal arterial oxygen tension suggests a selective lowering of pulmonary vascular resistance and right-to-left shunting. Wider experience and careful attention to longer term toxicity will be necessary, but early indications are very exciting.

\section{Magnesium sulphate}

Abu-Osba and colleagues recently reported a series of cases in which newborns with severe persistent pulmonary hypertension unresponsive to conventional treatments and with predicted mortalities ranging from $94-100 \%$ were treated with high dose intravenous magnesium sulphate. ${ }^{22}$ Seven of nine infants survived. Treatment was associated with improvements in arterial oxygen tension and haemoglobin saturation, decreased arterial carbon dioxide tension, and increased $\mathrm{pH}$. The mechanism believed responsible for the observed changes was reduced pulmonary pressure from muscle relaxation. This intriguing treatment will require more study.

\section{Summary and conclusions}

The past decade has witnessed technological advancements which are unparalleled in neonatology. ECMO has been demonstrated to be a powerful rescue treatment, but has perhaps been overutilised and is not universally available. Alternative treatments have been shown to be both safe and efficacious in the management of infants with respiratory failure. Direct head to head clinical trials will probably be necessary to establish appropriate criteria and indications for use, given the wide diversity of pathophysiology these unique patients present.

Section of Newborn Services,

STEVEN M DONN

Holden Neonatal Intensive Care Unit,

University of Michigan Medical Center,

L3023 Women's Hospital/0254,

200 East Hospital Drive,

Ann Arbor,

Michigan 48109-0254, USA 
1 Donn SM. ECMO indications and complications. Hosp Prac 1990; 25: 143-57.

2 Extracorporeal Life Support Organization. ECMO registry report. Ann Arbor, Michigan: ELSO, July 1993.

3 Bartlett RH, Roloff DW, Cornell RG, Andrews AF, Dillon PW, Zwischenberger JB. Extracorporeal circulation in neonatal respiratory failure: a prospective randomized study. Pediatrics 1985; 76: 479-87.

4 O'Rourke PP, Crone RD, Vacanti JP, et al. Extracorporeal membrane oxygenation and conventional medical therapy in neonates with persistent oxygenation and conventional medical therapy in neonates with persistent pulmonary hypertension of the

5 Nicks J, Bartlett RH. Extracorporeal membrane oxygenation and other new modes of gas exchange. In: Carlo WA, Chatburn RL, eds. Neonatal respiratory care. Chicago: Year Book Medical Publishers, 1988: 394-408.

6 Faix RG, Pryce CJE. Shock and hypotension. In: Donn SM, Faix RG, eds. Neonatal emergencies. Mount Kisco, NY: Futura Publishing, 1991: 371-85.

7 Deluga KS. Persistent pulmonary hypertension of the newborn. In: Donn SM, Faix RG, eds. Neonatal emergencies. Mount Kisco, NY: Futura PM, Faix RG, eds. Neonat

8 Peckham GJ, Fox WW. Physiologic factors affecting pulmonary artery pressure in infants with persistent pulmonary hypertension. $\mathcal{f}$ Pediatr pressure in infants

9 Drummond WH, Gregory GA, Heymann MA, et al. The independent effects of hyperventilation, tolazoline, and dopamine on infants with persistent pulmonary hypertension. $\mathcal{F}$ Pediatr 1981; 98: 603-11.

10 Wung JT, James LS, Kilchevsky E, et al. Management of infants with severe respiratory failure and persistence of fetal circulation. Pediatrics 1985; 76: 488-94.

11 Dworetz AR, Moya FR, Sabo B, et al. Survival in infants with persistent pulmonary hypertension without extracorporeal membrane oxygenation. Pediatrics 1989; 84: 1-6.
12 Donn SM, Nicks JJ, Bandy KP. Proximal high frequency jet ventilation of the newborn. Pediatr Pulmonol 1985; 1: 267-71.

13 Baumgart S, Hirschl RB, Butler SZ, Coburn CE, Spitzer AR. Diagnosisrelated criteria in the consideration of extracorporeal membrane oxygenation in neonates previously treated with high-frequency jet ventilation. Pediatrics 1992; 89: 491-4.

14 Hart M, Finley V, Wales R. High frequency jet ventilation and persistent pulmonary hypertension. Proceedings of the seventh conference on high

15 Carter JM, Gerstmann DR, Clark RH, et al. High-frequency oscillatory ventilation and extracorporeal membrane oxygenation for the treatment of acute neonatal respiratory failure. Pediatrics 1990; 85: 159-64.

16 Franckx J, Vandenplas Y, Sacre-Smits L. Volume limited ventilation for treatment of severe respiratory distress in neonates. Acta Anaesthesiol Belg 1984; 35 (suppl): 379-86.

17 Bandy KP, Nicks JJ, Donn SM. Volume-controlled ventilation for severe neonatal respiratory failure. Neonatal Intensive Care 1992; 5: 70-3.

18 Shaffer TH, Wolfson MR, Greenspan JS. Perflourochemical liquid ventilation during early development. In: Lafeber HN, ed. Fetal and neonatal physiological measurements. Amsterdam: Excerpta Medica, 1991: 225-30.

19 Ignarro LJ, Buga GM, Wood KS, et al. Endothelium-derived relaxing factor produced and released from artery and vein is nitric oxide. Proc Natl Acad produced and released from

20 Roberts JD, Lang P, Polander DM, et al. Inhaled nitric oxide in persistent pulmonary hypertension of the newborn. Lancet 1992; ii: 818-9.

21 Kinsella JP, Shaffer E, Neish SR, et al. Low dose inhalational nitric oxide in persistent pulmonary hypertension of the newborn. Lancet 1992; ii: 819-20.

22 Abu-Osba YK, Galal O, Manasra K, Rejjal A. Treatment of severe persistent pulmonary hypertension of the newborn with magnesium sulphate. Arch Dis Child 1992; 67: 31-5. 